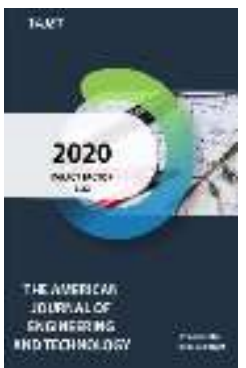

Journal Website: http://usajournalshub.c om/index,php/tajet

Copyright: Original content from this work may be used under the terms of the creative commons attributes 4.0 licence.

\section{Artificial Intelligence, Ensuring Information Security In Virtual Robots And Extensive Use Of Smart Systems}

\author{
Zarif Zafarovich Kodirov \\ Doctoral Student, Assistant Of Department Of Information Security, Tashkent University Of \\ Information Technologies, Tashkent, Uzbekistan \\ Majid Malikovich Karimov \\ Doctor Of Technical Sciences, Professor, General Director Of The State Testing Center, \\ Tashkent, Uzbekistan \\ Komil Axmatovich Tashev \\ Phd Of Technical Sciences, Vice Rector For Scientific Affairs, Tashkent University Of \\ Information Technologies Tashkent, Uzbekistan \\ Sherzod Rajaboyevich G'ulomov \\ Phd Of Technical Sciences, Associate Professor, Department Of Information Security, \\ Tashkent University Of Information Technologies, Tashkent, Uzbekistan \\ Munisa Xamza Qizi Islomova \\ Student, Faculty Of Software Engineering, Tashkent University Of Information Technologies, \\ Tashkent, Uzbekistan
}

\title{
ABSTRACT
}

This paper presents the first-generation of design of two classes of software programs with artificial intelligence. The robots created with intellect* will help people in different fields of the life and they work for people.

Intellect - the thinking ability of a person.

\section{KEYWORDS}

Intellect, artificial intelligence, Cortana, Alisa.

\section{INTRODUCTION}

Intellect-thinking ability of a person.

Artificial intelligence - feature of automated and information systems that embody some of the functions of person intellect.
Artificial intelligence represents the ability of a person to reason that is relatively stable, such as the ability to receive information and use it to solve certain issues. 
The issues that are solved on the computer, even though some are quite complex, are not intellectual. In this place, the question arises whether the arithmetic actions performed in the school are not intellectual. In this expression there is some kind of ambiguous element related to the issue. The exact algorithm for solving this issue is unknown or does not exist. For a reader who does not know what standard materials are the method of solving the issue, the answer is searching action, which requires a clear smart function. The reader who knows the method will automatically solve the problem in this type.

\section{USING ARTIFICIAL INNTELIGENCE IN ROBOTS}

\section{A. Solving issues}

Issue is so complicated, if a clear method (algorithm) of solving it is found and a suitable program is developed, it is considered that its work is solved manually or truly creatively. For the computer, however, it usually remains only part of the mechanical operation of the case. But this is not in all issues.

There are such situations when the algorithm of solving the issue is not found at all, and even when the most time is spent, it can not be solved on the computer. Such issues are not uncommon. Among these, it is possible to find templates, create chessplaying programs, automate translations, etc.

When a person faces such issues, he does not seek to find some kind of unique solution or effective method, but tries to use different methods and ways, sources of information in the process of solving the issue. Work in the field of artificial intelligence consists mainly of "teaching" the computer to use its less-mastered methods and more effectively methods.Nowadays, a lot of work has been done in this area, that is, programs have been created to solve intellectual tasks.

Cortana - Virtual voice assistant enhanced with artificial intelligence controls for Microsoft Windows

\section{B. Optimal variant of solving problem with proper interface}

The computer selects the optimal variant of solving the problem. If the optimal option is not chosen and the issue will be solved directly, a lot of time will be spent on it. For example, there may be several options to go from your house to the Lyceum. When you first go to the Lyceum to find the closest way, you will be need to help. There is a common similarity in such matters that they are solved using the logical thinking method.

"Interface" consists of two words "inter" International and "face" - person, it means universal translator. It embodies the concepts of communication tools, a repository of knowledge and a programmer. With the help of the interface is divided able to communicate directly with the computer. With the help of expert systems, it will be possible to understand the processes in complex systems, diagnose, adopt solutions, develop and verify the plans, hypotheses of various works, as well as the production of mathematical models and rules, taking advantage of the knowledge available in the computer. Knowledge can be conditionally divided into three according to the interface to put in it.

\section{ELECTRICAL SYSTEMS}

First -intellectual information search systems. The second - calculation-logical systems. Third-expert systems.

Expert systems are an artificial intelligence system that includes the knowledge database that has the sum of the summary rule and mechanism.

Intellectual information search systems allow communication to take place very close to the natural language.

Technologies similar to our program are as follows:

\section{Cortana}

Phone 8.1, Microsoft Band, Windows 10, Android, Xbox One and iOS 
The personal assistant Cortana is designed to enter the user's requirements. You can use the search engine by referring to it. Cortana is called by pressing the "Search" button. The desired request can be entered with input devices or by voice. It finds the necessary information based on the search results in the Bing system, Foursquare and user's personal files.

- Cortana is a local and global search engine, but if there is no internet network, then the search system absolutely does not work.
- Cortana search system is developed for all platforms.

- Data in the program can also be entered manually and by voice.

- Voice recognition is carried out step-by-step through word combinations.

\section{O \\ Hey Cortana}

\section{ALISA}

Alisa is a virtual voice assistant created by Yandex. It recognizes natural speech, simulates live communication, asks questions to users and solves practical problems. Alisa smartphones, including Yandex.Telephone works in cars and Yandex.

Through the voice can communicate with the assistant, and it is possible to enter requests from the keyboard. "Alisa" responds directly in the communication interface or displays the results of the request or the desired application. In addition with answering questions, Alisa solves practical tasks: turns on music, turns on calls, calls a taxi, etc.

- Alisa works mainly in the global search system.

- Alisa search system works on the internet, a person can not use the program who is not online.

- The program is created only for the Yandex search system.

- Alisa receives the voice well and answers.

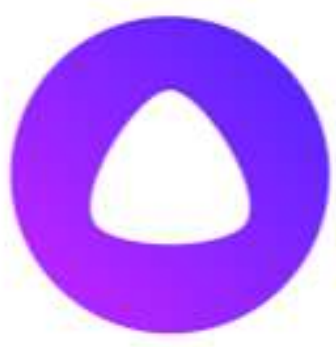

Яндекс.Алиса 


\section{RECEPTION.UZ}

Reception UZ - virtual, a reception developed with artificial intelligence. The program recognizes a person's speech and returns him a worthy reaction, performs functions or processes. The program is used in offices, govemment offices, hospitals, road transport stations.

Program registers visitors. Here, data can be entered manually or by voice into the program. For interesting, the program is characterized by the fact that they can communicate, answer questions, return suitable reaction to questions.

- Reception UZ is a virtual reception.

- Commands are entered manually and by voice to the software.

- The program recognizes human speech, returns him a worthy answer.

- The program can work without an internet.

- Reception Uz software stores the entered data into the database and you can view them only by entering a special code.

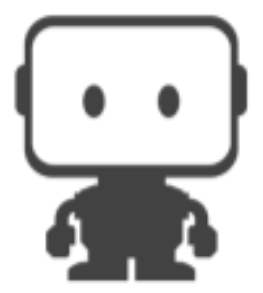

\section{Reception UZ}

\section{MATHEMATIC MODEL}
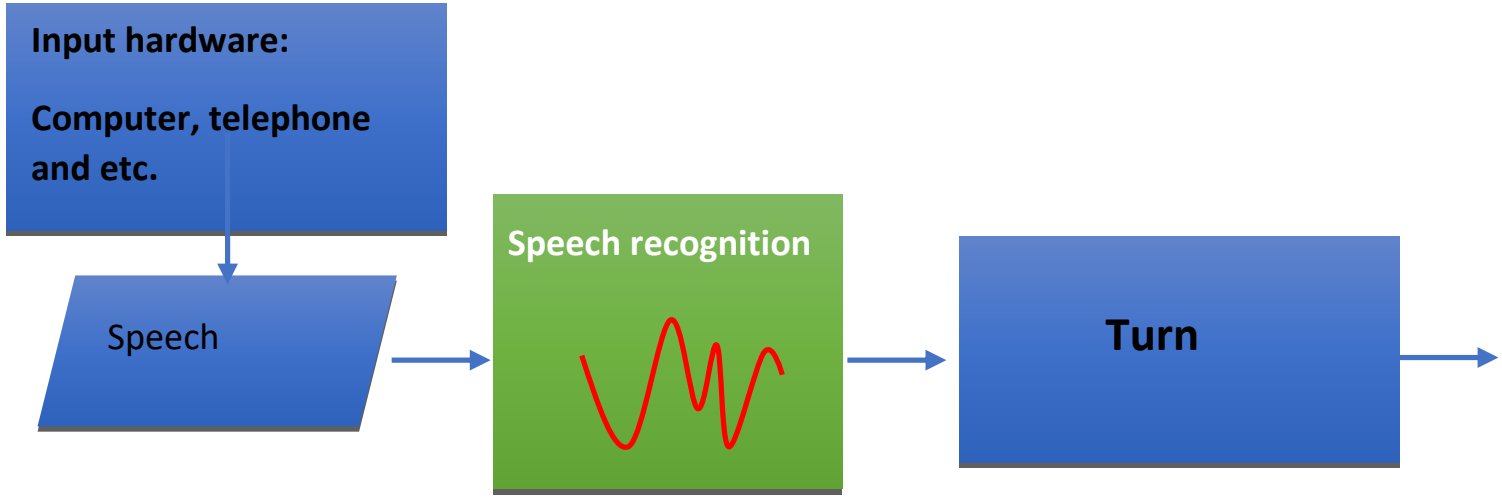

\section{Search from base}

Window of search results 
$\mathrm{s} 2(\mathrm{n})=\mathrm{s}(\mathrm{n})-\mathrm{a} * \mathrm{~s}(\mathrm{n}-1)$

Input of speech. s (n) speech sends to high

Here, s2 (n) - output signal and its value pass filter:

$H(z)=1-a * z-1$
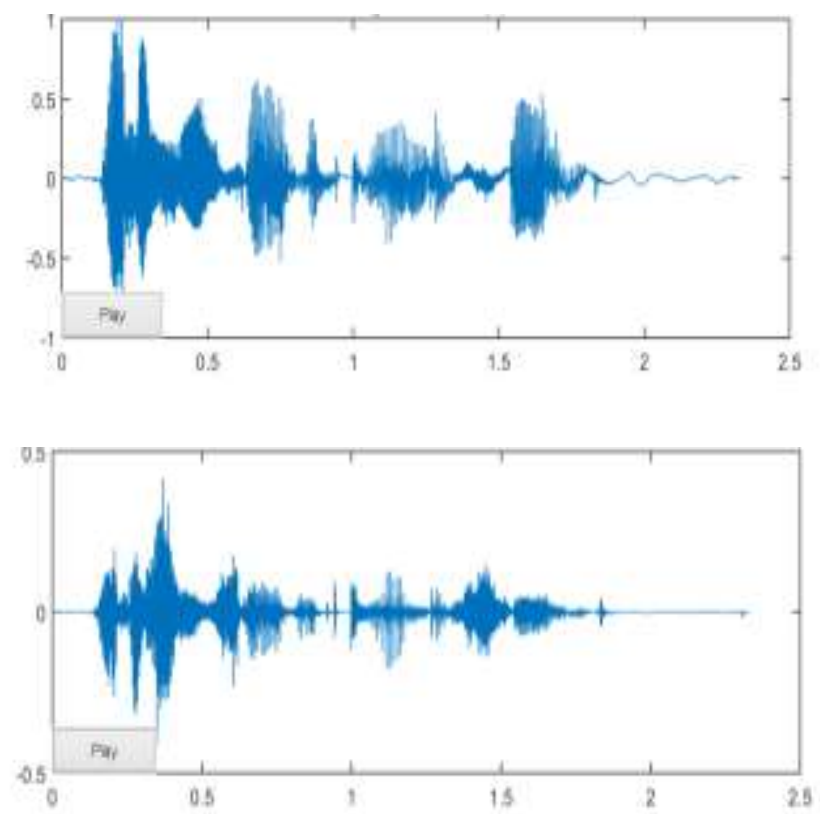

The input speech transmission is divided into frames 20 - $30 \mathrm{~ms}$, and the optional frame size is equal to $1 / 3 \sim 1 / 2$. If the sample speed is 16 $\mathrm{kHz}$ and the frame size is 320 , then the frame duration will be $320 / 16000=0.02$ seconds.

Hamming window: To ensure the continuity of the first and last points of each frame within the frame (in order to save detailed information in the next step), the clip must be multiplied by the window. If signal $\mathrm{s}$ inside $\mathrm{a}$ frame is selected with $s(n), n=0, \ldots N-1$, then the next signal in the Hamming window is $s$ $(n) * w(n)$, where $w(n)$ is denoted by the Hamming window:

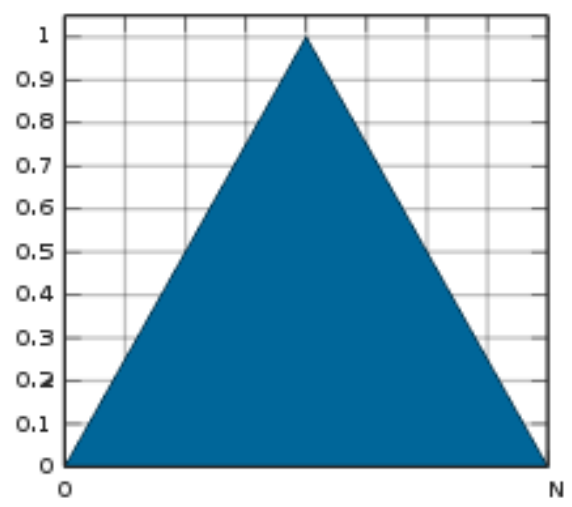




$$
(n, a)=(1-a)-\cos (2 p n /(N-1)), 0 \leqq n \leqq N-1
$$

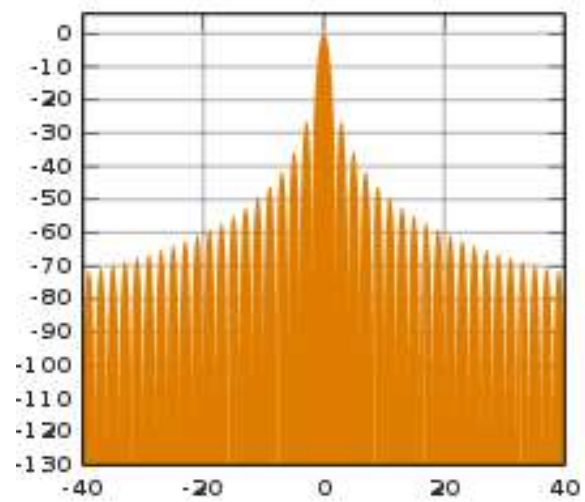

Fast Fourier transform or FFT: Spectral analysis shows that different timbres in speech signals correspond to different energy distribution by frequency. Therefore, we usually do FFT to get the frequency response of each frame.

If we do FFT in the frame, we will assume that the signal time inside the frame is continuous. If this is not the case, we can perform FFT, but it can produce false effects at the infinite frequency effect at the first and last points. There are two strategies to solve this problem:
To increase its duration at the first and last points, multiply each layer with a Hamming window.

Take a square of variable size, because it always contains a finite number of the main periods of the speech signal.

The second strategy has difficulties in practice, since it is not important to determine the main period. In addition, low sounds do not have a period at all. Thus, usually, before we implement FFT, we adopt the first strategy that will be hardened by the Hamming window. The following example shows the effect of multiplying the Hamming window.

\section{Real Sound Wave graph}

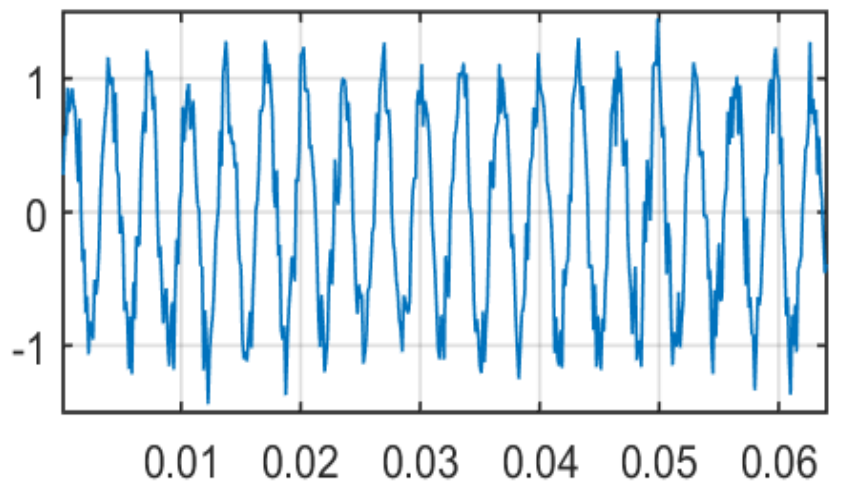


Filtered Sound Wave graph

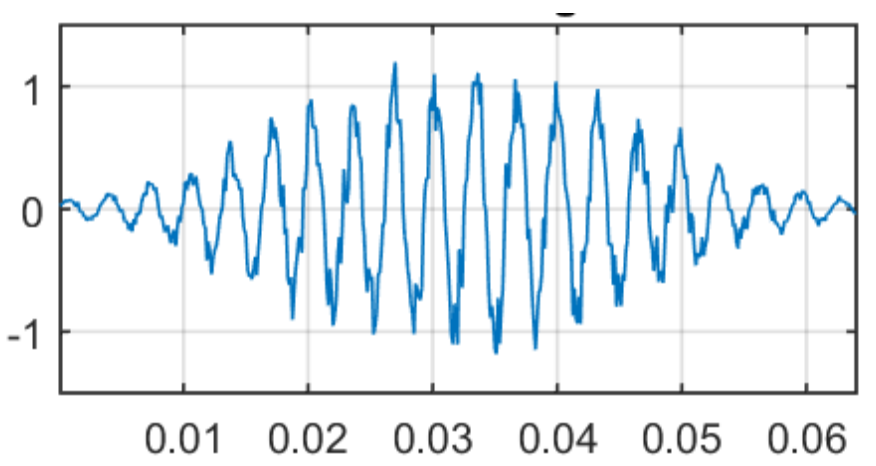

Energy spectrum graph (linear scale)

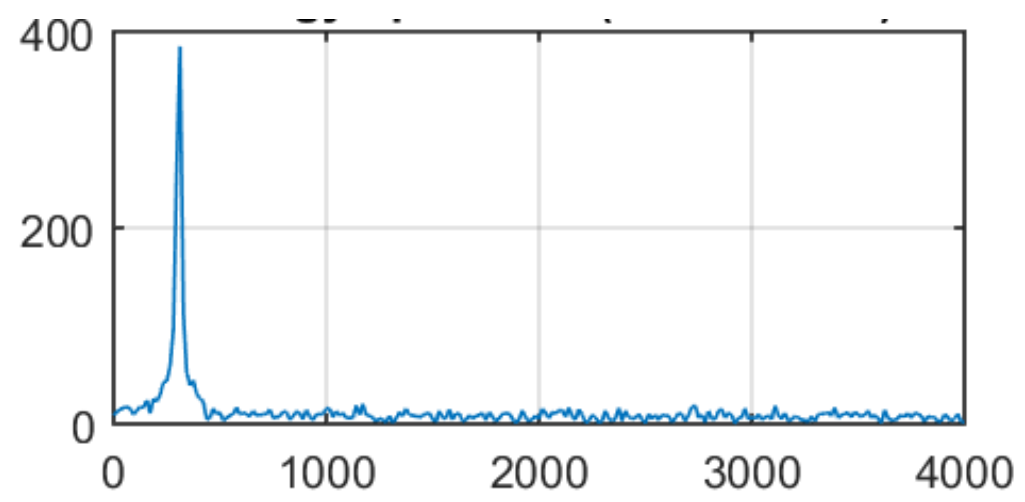

Energy spectrum graph (db)

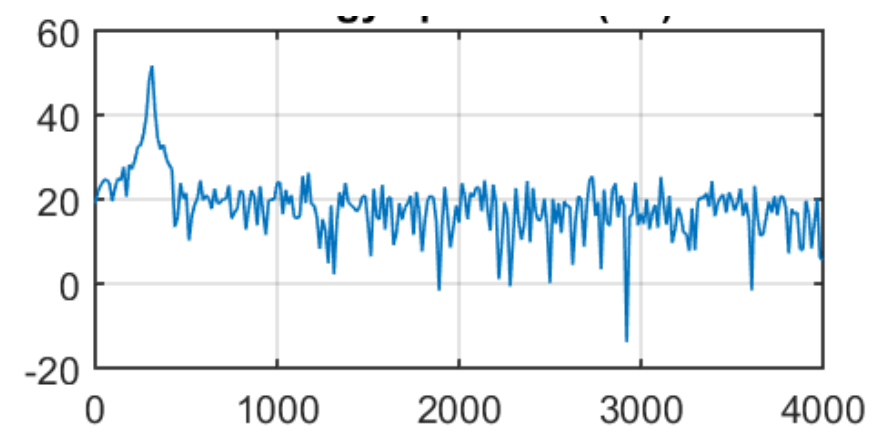

THE PURPOSE OF THE SOFTWARE PRODUCT

The Virtual Assistant usually manages itself and provides administrative, technical or creative (social) support to clients remotely from the home office. Virtual assistants are more independent than employees, they do everything within in the prescribed manner. 
Virtual assistants typically serve for businesses, and may support business leaders. It is estimated that there are 5,000-1,000,000 or 25,000 virtual assistants worldwide.

Common ways of communicating include Internet, email and phone call conferences, online jobs and a fax machine. Virtual assistants use technology such as Skype, Slack and Google Voice. The professionals in this business work on a contractual basis and have long-term partnerships.

In the last years, Virtual assistants have introduced themselves to many major businesses.

Virtual assistants are companies that operate as independent entities and offer a wide range of products and services to businesses and consumers. Virtual assistants usually take on a variety of functions, including secretarial work, website editing, social media marketing, customer service and so on. The virtual environment has changed so efficiently that it attracts the attention of others. Virtual assistants use a variety of business resources, but many of them have years of experience in the "real" (non-virtual) business world, or several years of online or remote experience.

The purpose of this software is to make people communicate with technology. Now anyone can easily manage a computer. Our virtual software is mainly used in offices, lounges, hotels, call centers, and wherever the virtual receiver service is.

Our software products can adapt to any environment and work in any condition. The most important thing is that the software can work offline or without internet resources, thus preventing additional costs.

For instance, before you hire an employee, you should consider his work experience, how many years of experience will determine his level of work, and it will take many years for him to enter his work environment. In order to maximize your work experience, the Virtual Assistant offers itself a day, whichever you choose.

\section{THE INTERFACE OF SOFTWARE PRODUCT}

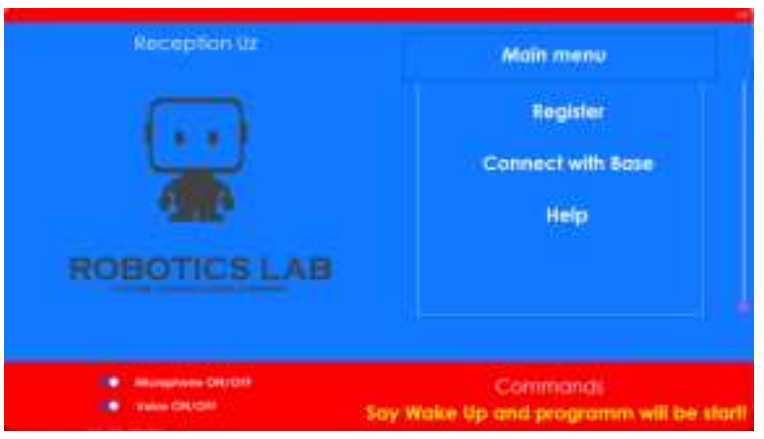

Fig 1.1 The interface of Reception Uz software.

To make the interface of software, we use the graphic opportunities of C\# WinForms (Bunifu). All user-friendly interface is provided.
You can turn the Virtual Robot headset on or off at any time. It helps to work. This will help the program to run smoothly. After you start 
the program, you will wake up the virtual robot by saying the key word (Wake Up). Then we have a command prompt with the help keyword. This version of our virtual assistant acts as a recipient. It has 3 basic and many auxiliary features.

1. Register - This feature allows anyone who has come to the reception to enter the database, including the name of the visit, the name of the host, and the contact details. Only this admin can see this information.

2. Connect with Base - This function connects to the Admin database and browses the data of each registered person.

3. Help - This function allows you to view all keywords and their functions in the software environment.

To call Register's command it is enough to know the "register me "keyword in the virtual robot, if you do not have this information, you can go to the help menu. After you open the Register window, the program interface will be used to enter the image and data you need to access the webcam. After you have entered all the data, you can save it to the database using the Save Date keyword. No other person can access your information except Admin. After you connect to the database (Admin) you can view the data of all registered employees. The "Next key" is used to move to the next person. To leave the base, the key "Close base" is used. Our virtual robot will also be able to communicate with him so that he does not get bored. That is, you will receive interesting answers from a limited number of questions. In later generations of software, a new feature will be added. It gives him an artificial intelligence. You might be wondering what. It is a function of increasing its vocabulary. In the future, if our software is used on a large scale, many people will be able to communicate with him, and he will record the answer that is unknown to him from the people he or she is communicating with. Base is expanding. In the end, it becomes an artificial intelligence that can react to any of your answers. The database is monitored by the administrator to prevent false answers. Incorrect responses will be removed from the database. This will ensure that it is accurate and accurate. 


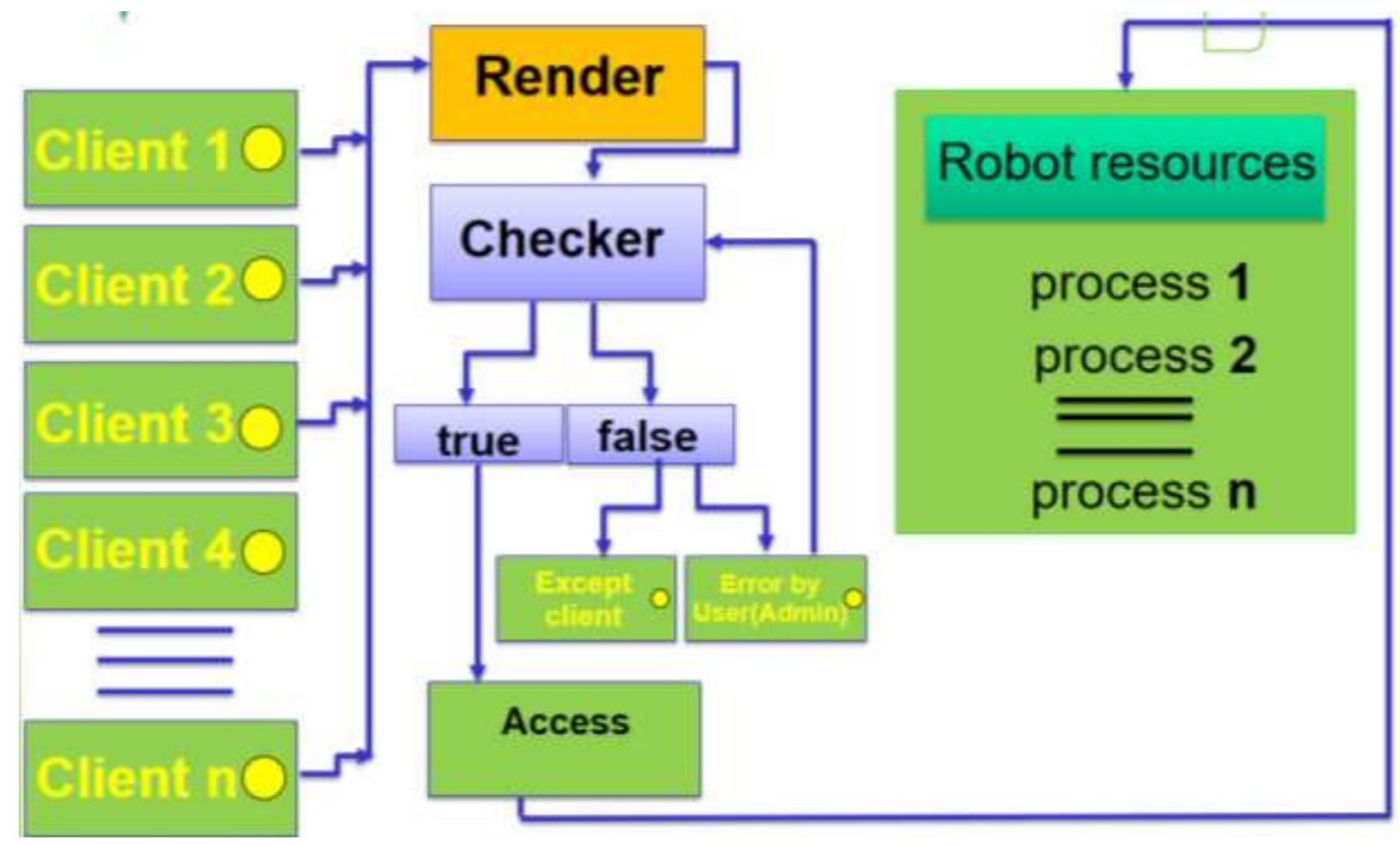

Programming tools used to create a program

\section{CONCLUSIONS}

Reception Uz was developed in a Visual Studio 2019 C \# WinForms environment. We used
Bunifu design components in our program. Microsoft Speech Library was used to differentiate the sound. The System Speech library was used to read the text.

Library Collection:

System;

System.Drawing;

System.Windows.Forms;

System.Speech.Synthesis;

Microsoft.Speech.Recognition;

System.IO;

Emgu.CV;

Emgu.CV.Structure;
//To work with system

// To create WinForm

// To create a form

//To read the text

//For voice recognition

//To save the image to the database

//To work with images

//To launch the camera 
System.Data.OleDb;

System.Media;

\section{REFERENCES}

1. Zhang, J. Experimental study on a novel fuzzy control method for static pressure reset based on the maximum damper position feedback. Energy Build. 2015,108, 215-222

2. Guerrero, J.; Torres, J.; Creuze, V.; Chemori, A.; Campos, E. Saturation based nonlinear PID control for underwater vehicles: Design, stability analysis and experiments. Mechatronics 2019,61, 96-105.

3. Badia, M.; Qian, J.P.; Fan, B.L. Artificial neural networks and thermal image for temperature prediction in apples. Food Bioprocess Technol. 2012,9, 1089-1099.

4. Badia, M.; McCarthy, R. Data estimation methods for predicting temperatures of fruit in refrigerated containers. Biosyst. Eng. 2016,151, 251-272.

5. Ryu, S.H.; Moon, H.J. Development of an occupancy prediction model using indoor environmental data based on machine learning techniques. Build. Environ. 2016,107, 1-9.

6. Fujimori, A.; Ohara, S. Order Reduction of Plant and Controller in Closed Loop Identification based on JointInputOutput Approach. Int. J. Control Automat. Syst. 2017,15, 1217-1226.

7. Ko, J.S.; Huh, J.H.; Kim, J.C. Improvement of Temperature Control Performance of Thermoelectric
Dehumidifier Used Industry 4.0 by the SF-PI Controller. Processes 2019,7, 98.

8. Nunes, M.C.N.; Nicometo, M.; Emond, J.P.; Badia-Melis, R.; Uysal, I. Improvement in fresh fruit and vegetable logistics quality: Berry logistics field studies. Philos. Trans. R. Soc. A Math. Phys. Eng. Sci.2014,372, 20130307

9. Li, X.M.; Zhao, T.Y.; Zhang, J.L.; Chen, T.T. Predication control for indoor temperature time-delay using Elman neural network in variable air volume system. Energy Build. 2017,154, 545-552

10. Nunes, M.C.N.; Nicometo, M.; Emond, J.P.; Badia-Melis, R.; Uysal, I. Improvement in fresh fruit and vegetable logistics quality: Berry logistics field studies. Philos. Trans. R. Soc. A Math. Phys. Eng. Sci.2014,372, 20130307.

11. https://en.wikipedia.org

12. https://link.springer.com 